\title{
Tax contributes apoptosis resistance to HTLV-1-infected T cells via suppression of Bid and Bim expression
}

\author{
A Mühleisen ${ }^{1}$, M Giaisi ${ }^{1}$, R Köhler ${ }^{1}$, PH Krammer ${ }^{1}$ and M Li-Weber ${ }^{\star, 1}$
}

The human T-lymphotropic virus type 1 (HTLV-1) is the etiological agent of adult T-cell leukemia (ATL). HTLV-1 Tax has been shown to have a prosurvival role in infected T cells by enhancing expression of the Bcl-2 family of antiapoptotic proteins. In this study, we show that the expression of proapoptotic BH3-only proteins Bim (Bcl-2-interacting mediator of cell death) and Bid (BH3-interacting domain death agonist) is diminished in HTLV-1-infected leukemic cells. Using a Tax-inducible system and a transient overexpression approach, we demonstrate that Tax downregulates Bid and Bim expression at the transcriptional level. We show that reinforced expression of Bim and Bid in HTLV-1-infected T-cell lines sensitizes CD95/TRAIL- and anticancer drug-induced apoptosis. Furthermore, we show that Tax suppresses Bid and Bim expression by enhancing hypoxia-inducible factor-1 $\alpha$ (HIF-1 $\alpha$ ) protein expression. siRNA knockdown of HIF-1 $\alpha$ or chemical inhibition of the transactivation activity of HIF-1 $\alpha$ resulted in an increase in Bid and Bim expression and, consequently, in an increase in CD95/TRAIL- and anticancer drug-induced apoptosis in HTLV-1-infected leukemic T-cell lines. Our study provides evidence that besides upregulation of prosurvival Bcl-2 proteins, Tax may also confer apoptosis resistance to HTLV-1-infected T cells by suppressing the expression of the proapoptotic BH3-only proteins Bim and Bid.

Cell Death and Disease (2014) 5, e1575; doi:10.1038/cddis.2014.536; published online 18 December 2014

The adult T-cell leukemia (ATL) was first described in 1977. Hereafter, the exclusive causal agent for ATL was identified to be a retrovirus, the human T-lymphotropic virus type 1 (HTLV-1), in 1980. ${ }^{1}$ At present, an estimated 10 million people worldwide are infected with HTLV $-1 .{ }^{2}$ Although only a small portion of virus carriers $(26.6 \%$ for males and $2.1 \%$ for females) will develop ATL, those patients have a poor prognosis with a survival range of $<1$ year after disease onset. $^{3,4}$

After more than 30 years of intensive studies, evidence has shown that the viral protein Tax has a key role in promoting viral spread and it is also one of the essential proteins involved in oncogenesis through multiple mechanisms, for example, promoting G1-S progression, enhancing the PI3K-AKT signaling pathway, inducing DNA hyper-replication, decreasing DNA repair, constitutive activation of NF- $k B$ and suppression of apoptosis. ${ }^{4,5} \mathrm{We}$ and others have previously shown that HTLV-1 Tax enhances expression of the caspase-8 inhibitory protein c-FLIP and the Bcl-2 family of antiapoptotic proteins $\mathrm{Bcl}-2, \mathrm{Bcl}-\mathrm{xL}, \mathrm{Mcl}-1$ and Blf-1, and, consequently, causes apoptosis resistance and survival of HTLV-1-infected T cells. ${ }^{6-11}$ So far, most studies focused on the effect of Tax on antiapoptotic proteins. Little is known about the influence of HTLV-1 Tax on proapoptotic proteins. As pro- and antiapoptotic proteins are equally important in the regulation of death and life of cells, we asked whether Tax-mediated apoptosis resistance and survival also involves deregulation of proapoptotic genes.

To date, the best studied mammalian proapoptotic proteins are the apoptotic effector proteins Bak (Bcl-2 antagonist/killer) and $\mathrm{Bax}$ (Bcl-2-associated $\mathrm{X}$ protein), which contain three $\mathrm{BH}$ domains $(\mathrm{BH} 1, \mathrm{BH} 2 \text { and } \mathrm{BH} 3)^{12,13}$ and the $\mathrm{BH} 3-$ only proteins Bad (Bcl-2 antagonist of cell death), Bid (BH3-interacting domain death agonist), Bim (Bcl-2-interacting mediator of cell death), Noxa and PUMA (p53-upregulated modulator of apoptosis). ${ }^{14,15}$ Cell death induced by $\mathrm{BH}$-only proteins is absolutely dependent on the presence of Bak and Bax, indicating that they act upstream of these effector proteins in the apoptotic signaling pathway. ${ }^{14,15}$ Functionally, BH3-only proteins can be divided into activator and sensitizer proteins depending on their ability to interact with other members of the $\mathrm{Bcl}-2$ family. The activator $\mathrm{BH} 3-o n l y$ proteins Bid, Bim and PUMA bind not only to all antiapoptotic Bcl-2 members but are also capable of activating Bak and Bax directly. ${ }^{16-20}$ The sensitizer BH3-only proteins, however, only interact with a limited set of antiapoptotic proteins, for example, Bad binds to $\mathrm{Bcl}-2, \mathrm{Bcl}-\mathrm{xL}$ and $\mathrm{Bcl}-\mathrm{w}$, whereas Noxa exclusively interacts with $\mathrm{Mcl}-1$ and $\mathrm{A} 1 .^{17}$

In this study, we show that Bid and Bim expression is suppressed in HTLV-1-infected leukemic T-cell lines. We also show that Tax downregulates Bid and Bim expression through the elevation of the protein levels of the transcription factor HIF-1a (hypoxia-inducible factor-1a). Furthermore, we show

\footnotetext{
${ }^{1}$ Tumor Immunology Program D030, German Cancer Research Center (DKFZ), Heidelberg 69120, Germany

*Corresponding author: M Li-Weber, Tumor Immunology Program D030, German Cancer Research Center (DKFZ), Im Neuenheimer Feld 280, Heidelberg 69120, Germany. Tel: +49 6221 423748; Fax: +49 6221 411715; E-mail: m.li-weber@dkfz-heidelberg.de

Abbreviations: HTLV-1, human T-lymphotropic virus type 1; ATL, adult T-cell leukemia; Bid, BH3-interacting domain death agonist; Bim, Bcl-2-interacting mediator of cell death; HIF-1 $\alpha$, hypoxia-inducible factor- $1 \alpha$

Received 19.8.14; revised 28.10.14; accepted 5.11.14; Edited by T Brunner
} 
that suppression of Bid and Bim expression by Tax may have a significant impact on apoptosis resistance to CD95, TRAIL-R stimulation and anticancer drugs in HTLV-1-infected T cells.

\section{Results}

HTLV-1-infected T cells are highly resistant to anticancer drug-induced apoptosis. Up to date, clinical trials on ATL with even a wide range of combination chemotherapy achieved only limited success. ${ }^{3}$ To investigate the molecular basis of their chemotherapy resistance, we chose four HTLV-1-infected T-cell lines, either derived from HTLV-1infected ATL patients (Hut-102 and SP) or HTLV-1 transformed by coculture (MT-2 and MT-4), and tested their response to etoposide and doxorubicin treatment. Compared with the non-HTLV-1-associated leukemic T-cell line Jurkat, all four HTLV-1-infected cell lines tested were highly resistant to etoposide- and doxorubicin-induced cell death at the doses that killed $>75 \%$ of Jurkat $\mathrm{T}$ cells (Figures $1 \mathrm{a}$ and $\mathrm{b}$ ). We then carried out a systematic analysis of the expression levels of proteins involved in apoptosis regulation by western blot analysis. Consistent with previous studies, ${ }^{6-10,21}$ all four HTLV-1-infected T-cell lines showed elevated expression levels of the antiapoptotic proteins (Figure 1c). Noticeably, the expression level of the proapoptotic effector protein Bax was also markedly increased in HTLV-1-infected T-cell lines
(Figure 1c). As Bax is essential for apoptosis induction, ${ }^{15}$ the observation above raises the question how HTLV-1 confers apoptosis resistance to infected cells when the expression levels of both anti- and proapoptotic proteins are enhanced.

Bid and Bim expression is downregulated in HTLV-1infected $\mathrm{T}$ cells. It has been shown that Bax activity can be directly enhanced by Bim, Bid and PUMA. ${ }^{18,22,23}$ Therefore, we asked whether the expression levels of Bim, Bid and PUMA are also altered to avoid an increase in apoptosis due to increased Bax expression. To address this question, we examined the expression levels of Bim, Bid and PUMA in HTLV-1-infected T-cell lines. Interestingly, we found that Bim and Bid expression levels were markedly downregulated in all HTLV-1-infected T-cell lines tested (Figure 2a). To confirm this observation, primary leukemic cells from two T-ALL patients and five HTLV-1-infected ATL patients were subjected to the analysis of Bim and Bid expression. Consistent with the observation from the ATL cell lines, primary ATL cells also showed a significantly reduced expression of Bim and Bid compared with the non-HTLV-1-infected T-ALL cells (Figure 2b).

We then asked whether Tax is responsible for the reduction of Bid, Bim and PUMA expression. To address this question, we first used an inducible system in which Jurkat cells were stably transfected with an estrogen receptor-tax fusion protein (ERtax) or an estrogen receptor-truncated tax (lacking the first

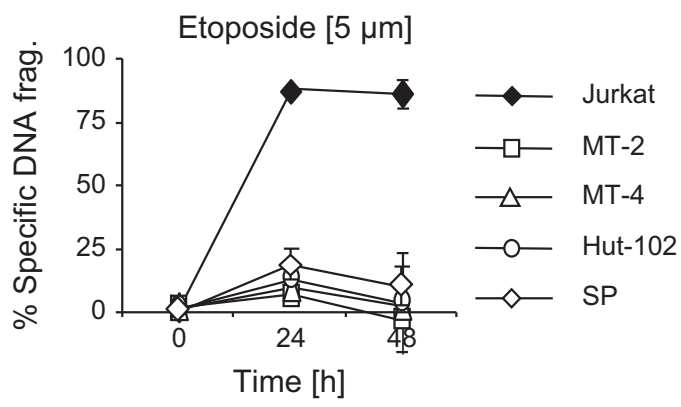

b

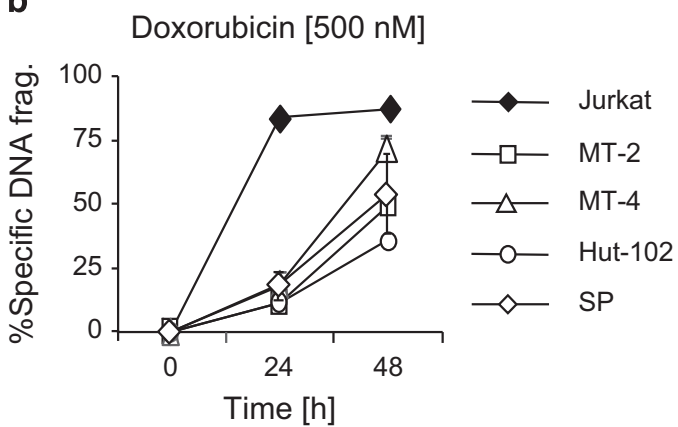

C

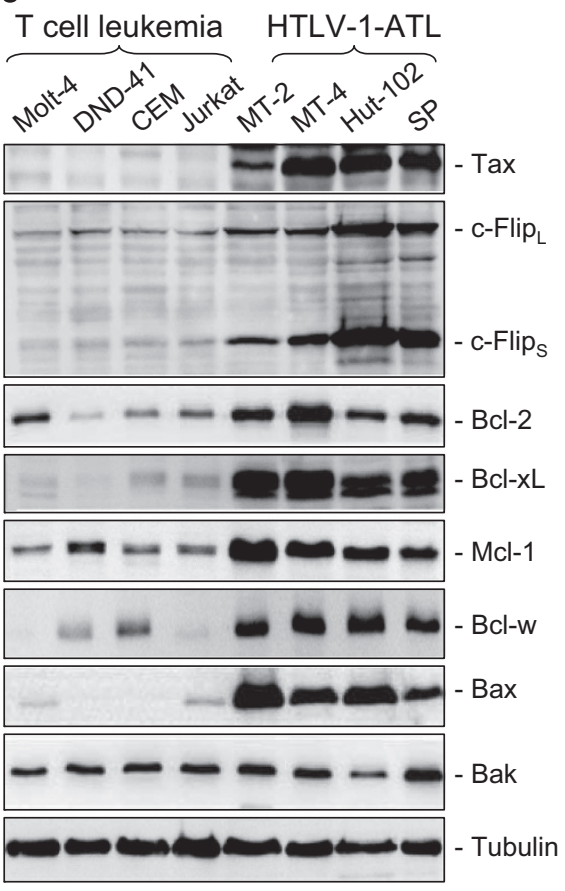

Figure 1 HTLV-1-infected T cells are highly resistant to anticancer drugs and show altered expression profiles of pro- and antiapoptotic proteins. (a and b) HTLV-1-infected T cells are resistant to etoposide- and doxorubicin-induced cell death. Cells from four HTLV-1-infected cell lines, MT-2, MT-4, Hut-102 and SP, were treated with etoposide (5 $\mu$ M) or doxorubicin $(500 \mathrm{nM})$ for 24 and $48 \mathrm{~h}$. Apoptosis was determined by DNA fragmentation. The non-HTLV-1-infected leukemic T-cell line Jurkat served as a control. Results are representative of three independent experiments each performed in duplicate assays. (c) Comparison of expression levels of pro- and antiapoptotic proteins between the HTLV-1infected T-cell lines and the non-HTLV-1-infected leukemic T-cell lines. Total cell lysates from MT-2, MT-4, Hut-102 and SP and the non-HTLV-1-infected leukemic T-cell lines Molt-4, DND-41, CEM and Jurkat were subjected to western blot analysis by antibodies against different anti- and proapoptotic proteins as indicated. Tax protein expression is used as a control of HTLV-1 infection. Representative blots from two to three independent experiments are shown 
a

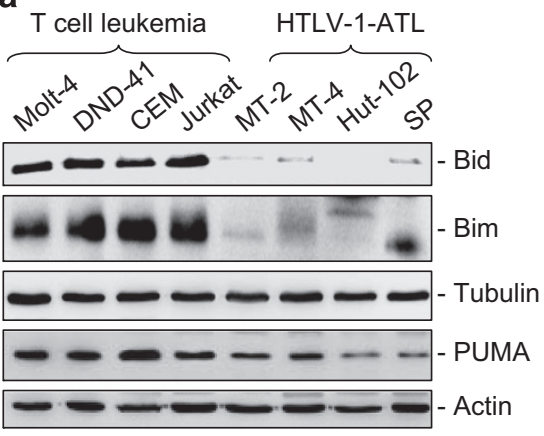

C

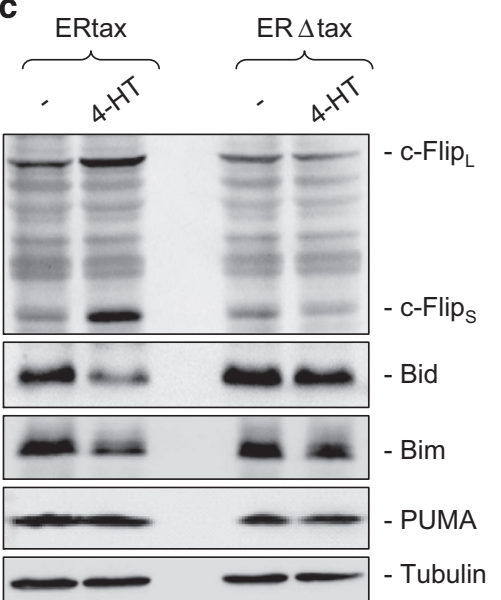

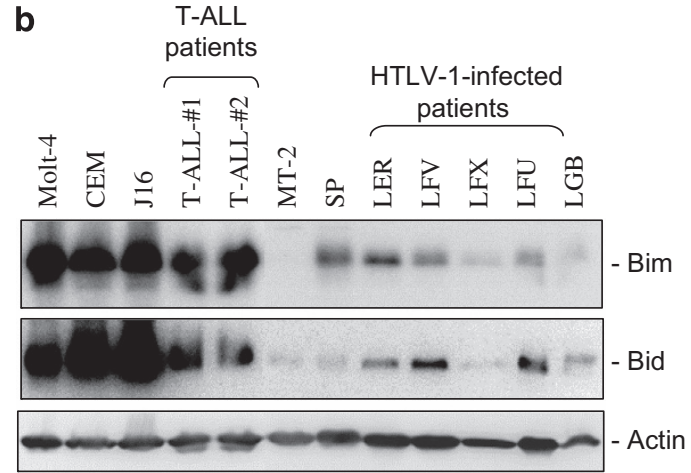

d

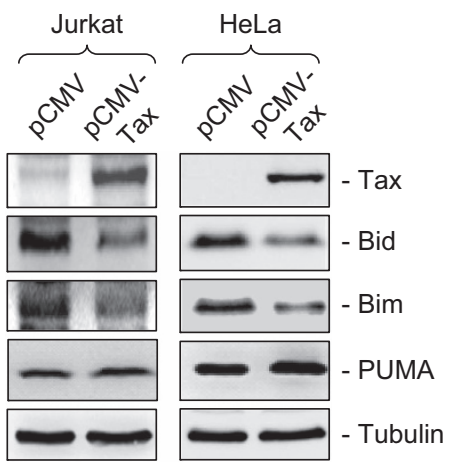

Figure 2 Bim and Bid expression is suppressed in HTLV-1-infected T cells. (a) Bim and Bid expression is suppressed in HTLV-1-infected T-cell lines. Total cell lysates from indicated HTLV-1-Tax-positive T-cell lines and non-HTLV-1-infected leukemic T-cell lines were subjected to western blot analysis by antibodies against Bim, Bid and PUMA. Representative blots from three independent experiments are shown. (b) Bim and Bid expression is suppressed in primary HTLV-1-positive ATL cells. Cells from HTLV-1-positive ATL patients were subjected to western blot analysis for Bim and Bid as in (a). The non-HTLV-1-infected cell lines Molt-4, CEM, Jurkat, the HTLV-1-infected MT-2 and SP cell lines and two T-ALL patients were used as controls. Representative blots from two independent experiments are shown. (c and $\mathbf{d})$ Downregulation of Bim and Bid expression correlates with Tax expression. Jurkat cells stably transfected with ERtax or ER $\Delta$ tax fusion proteins were stimulated by $4-\mathrm{TH}(5 \mu \mathrm{M})$ for $40 \mathrm{~h}$ and then subjected to western blot analysis with antibodies as indicated (b). As ERtax and ER $\Delta$ tax fusion proteins do not react with anti-Tax antibodies, c-Flip expression levels were used as positive controls for Tax function. Representative blots from three independent experiments are shown. (c) Jurkat and HeLa cells were transiently transfected with a Tax expression plasmid pCMV-Tax. Twenty-four hours after transfection, total cell lysates were subjected to western blot analysis with antibodies as indicated. Representative blots from two (Jurkat) and three (HeLa) independent experiments are shown

12 amino acids) fusion protein (ER $\Delta$ tax) ${ }^{24}$ ERtax can be activated by exogenous addition of 4-hydroxytamoxifen (4-HT). Using this inducible system, we observed that activation of ERtax but not ERAtax resulted in the suppression of Bim and Bid expression (Figure 2c). Consistent with our previous studies, ${ }^{8}$ the expression levels of c-FLIP proteins were enhanced by ERtax and served as a positive control. Next, to confirm this result, we carried out a transient transfection experiment using an expression plasmid to express Tax in either Jurkat or HeLa cells. The experiments showed that ectopic expression of Tax downregulated Bim and Bid expression in Jurkat and HeLa cells (Figure 2d). In contrast, PUMA expression was not influenced by Tax. These experiments demonstrate that Tax is responsible for the reduction of Bim and Bid expression.

Overexpression of Bid and Bim sensitizes HTLV-1 infected cells towards apoptosis. To investigate the importance of Bid or Bim in the regulation of sensitivity and resistance towards apoptosis induction in HTLV-1-infected
$\mathrm{T}$ cells, we transiently transfected expression plasmids containing either Bid or Bim cDNA into the HTLV-1-infected T-cell lines MT-2 and Hut-102. The experiments showed that ectopic expression of Bid or Bim in MT-2 and Hut-102 cells significantly enhanced the sensitivities of these cells towards etoposide-induced apoptosis (Figures $3 a-c$ and Supplementary Figures S1A and B). HTLV-1-infected $T$ cells have shown resistance to CD95L- and TRAIL-induced cell death. ${ }^{8,9,25}$ Consistent with the previous studies, all four HTLV-1-infected T-cell lines used in this study were highly resistant to CD95and TRAIL-induced apoptosis (Supplementary Figure S2). Ectopic expression of Bid or Bim also enhanced CD95- and TRAIL-induced cell death in MT-2 (Figures 3d-f) and Hut-102 cells (Supplementary Figures S1C and D).

To further confirm the importance of Bim and Bid in the contribution of apoptosis sensitivity, we carried out an siRNA approach to knockdown Bim and Bid in the non-HTLV-1infected T-cell line Jurkat. The experiments showed that knockdown of either Bim or Bid reduced apoptotic cell death induced by anti-CD95, TRAIL and etoposide (Figure 4). 


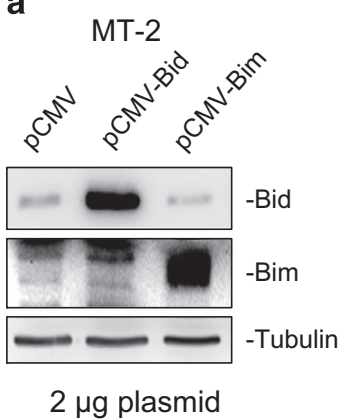

d

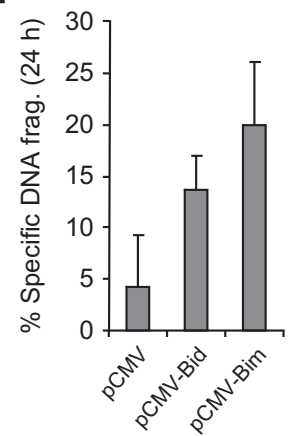

SK-TRAIL [50 ng/ml] b

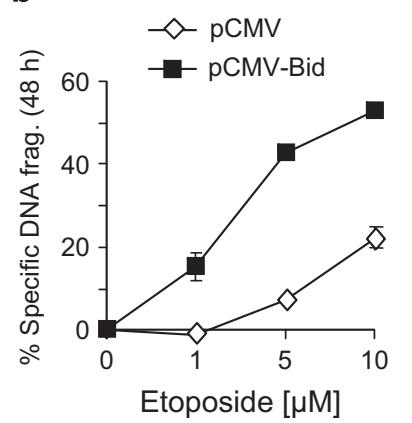

e

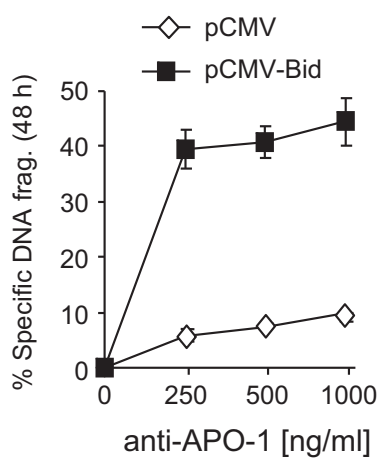

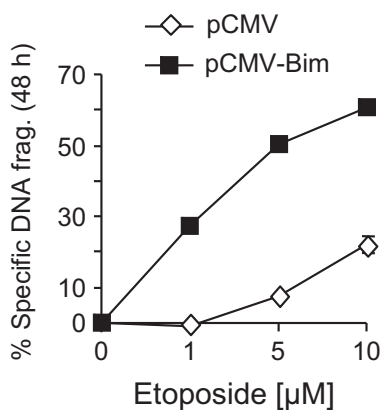

f

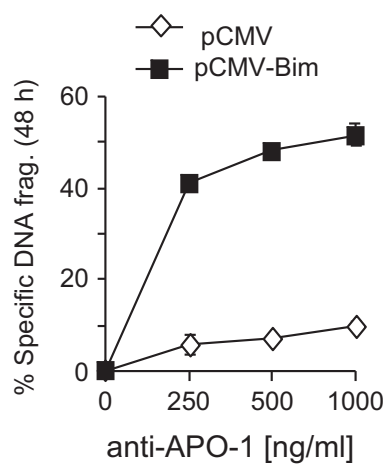

Figure 3 Overexpression of Bid and Bim sensitizes HTLV-1-infected T cells towards etoposide-, TRAIL- and anti-CD95-mediated apoptosis. (a) Overexpression of Bid and Bim in MT-2 cells. MT-2 cells were transfected with Bim or Bid expression plasmids as described in Materials and Methods. Forty-eight hours after transfection, expression efficiencies of Bim and Bid were controlled by western blot analysis. (b and $\mathbf{c}$ ) Overexpressions of Bid and Bim sensitize HTLV-1-infected T cells towards etoposide-induced apoptosis. Forty-eight hours after transfection, MT-2 cells were treated with different concentrations of etoposide for $24 \mathrm{~h}$ as indicated. Apoptotic cell death was determined by DNA fragmentation. Results are representative of two independent experiments each performed in duplicate assays. (d) Overexpressions of Bid and Bim sensitize HTLV-1infected T cells towards TRAlL-induced apoptosis. The experiment was performed as in (b and $\mathbf{c})$. Cells were treated with $50 \mathrm{ng} / \mathrm{ml}$ TRAlL for $24 \mathrm{~h}$. Results are representative of two independent experiments each performed in duplicate assays. (e and f) Overexpressions of Bid and Bim sensitize HTLV-1-infected T cells towards anti-CD95-induced apoptosis. The experiments were performed as in (b-d). Cells were treated with different concentrations of anti-APO-1 (CD95) antibody for $24 \mathrm{~h}$. Apoptotic cell death was determined by DNA fragmentation. Results are representative of two independent experiments each performed in duplicate assays

Knockdown of both proteins Bim and Bid further reduced antiCD95-, TRAIL- and etoposide-induced apoptosis (Figures 4e-h). Similar results were obtained when Bid was knocked down in HeLa cells (Supplementary Figure S3). Differences in the role of Bid in the regulation of CD95- and TRAIL-induced cell death were also observed. As shown in Figures $4 \mathrm{~b}$ and c, knockdown of Bid showed a stronger effect on CD95-mediated cell death compared with that seen in TRAIL-mediated cell death. These data demonstrate that Bim and Bid have an important role in promoting anti-CD95/TRAIL- and anticancer drug-induced cell death.

Tax suppresses Bim and Bid expression by the upregulation of HIF-1a protein levels. The experiments above show that HTLV-1-infected cells express no or only little amounts of Bid and Bim proteins (Figure 2). We then further investigated whether the expression of Bim and Bid was downregulated at the transcriptional level by a quantitative PCR (q-PCR) analysis. Consistent with the protein expression levels, the experiment showed no or only limited levels of expression of Bid and Bim mRNA compared with the nonHTLV-1-infected Jurkat T-cell line (Figure 5a). Thus, Bid and Bim expression may be suppressed at the transcriptional level in HTLV-1-infected cells.
It has been shown that the transcription factor HIF-1 suppresses $\mathrm{Bim}$ and $\mathrm{Bid}$ expression at low $\mathrm{O}_{2}$ or insufficient blood supply in hypoxic cells. ${ }^{26-29}$ We asked whether suppression of Bim and Bid expression in HTLV-1-infected cells involves a Tax-mediated increase in HIF-1a expression. To address this question, we first compared the expression levels of HIF-1 proteins in HTLV-1-infected and non-infected T-cell lines. Western blot analysis showed that the expression of HIF-1a, but not HIF-1 $\beta$, was strongly enhanced in the HTLV-1-positive T-cell lines (Figure $5 b$ ). We next investigated whether Bim and Bid expression is downregulated by Taxmediated upregulation of HIF-1 a expression. Using the ERtax/ $\mathrm{ER} \Delta$ tax- inducible system, expression of HIF-1a, but not HIF-1 $\beta$, was shown to be enhanced upon induction of Tax by 4HT (Figure 5c). The same results were obtained by transient transfection of a Tax expression plasmid into HeLa cells (Figure 5d). Ectopic expression of Tax in HeLa cells also led to a reduced expression of $\mathrm{Bim}$ and $\mathrm{Bid}$ at the transcriptional level (Figures $5 d$ and e). To further investigate the role of $\mathrm{HIF-1} a$ in the regulation of Bim and Bid expression in HTLV-1infected cells, we carried out an HIF-1a knockdown experiment using an siRNA approach. Knockdown of HIF-1a expression in MT-2 cells resulted in an increase in Bim and Bid expression and, consequently, to sensitization of MT-2 
a

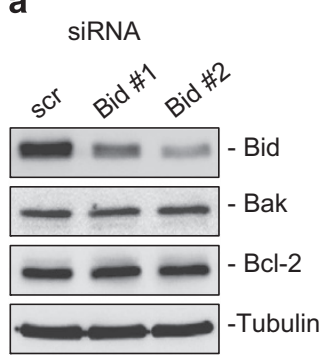

e

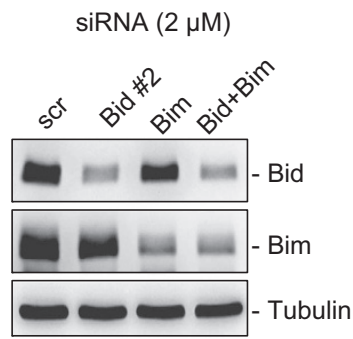

b

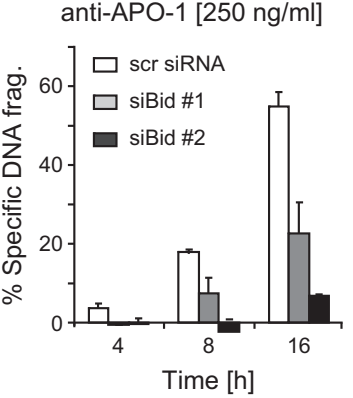

f anti-APO-1 [500 ng/ml]

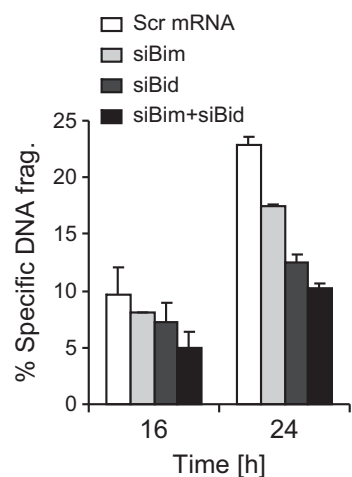

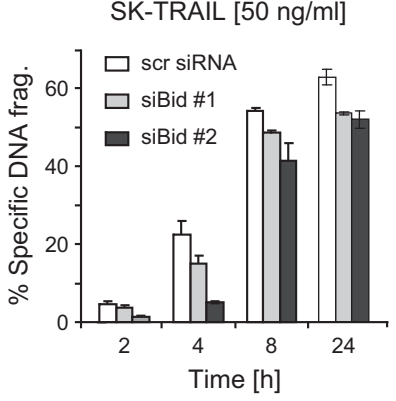

g

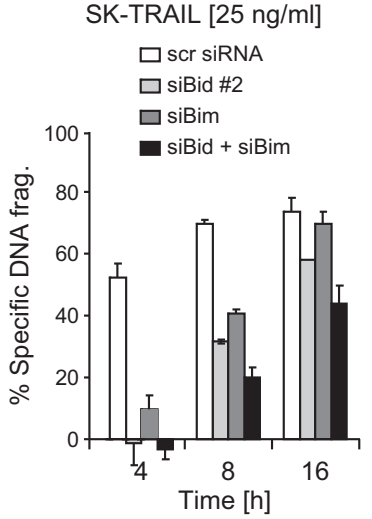

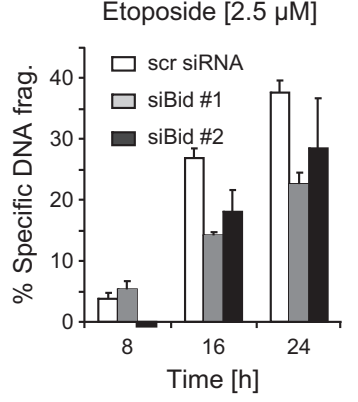

h

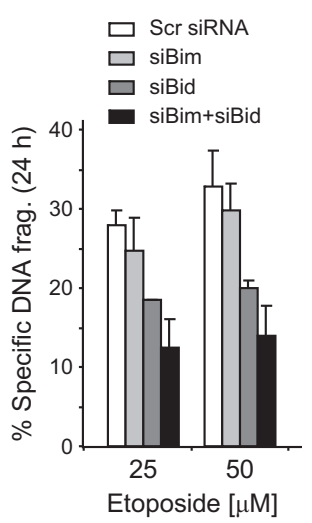

Figure 4 Knockdown of either Bim or Bid reduced apoptotic cell death induced by anti-CD95, TRAlL or etoposide. (a) Knockdown of Bid in Jurkat T cells. Jurkat T cells were transfected with two siRNAs specific for Bid. Seventy-two hours after transfection, the specificity and efficacy of knockdown were controlled by western blot with antibodies as indicated. (b-d) Knockdown of Bid reduced apoptotic cell death induced by anti-CD95, TRAIL or etoposide. Seventy-two hours after transfection, cells were treated with antiAPO-1 (CD95) $(250 \mathrm{ng} / \mathrm{ml})$, TRAIL $(50 \mathrm{ng} / \mathrm{ml})$ or etoposide $(2.5 \mu \mathrm{M})$ for different time periods as indicated. Apoptotic cell death was determined by DNA fragmentation. Results are representative of two independent experiments each performed in duplicate assays. (e) Knockdown of Bid, Bim or both in Jurkat T cells. Jurkat T cells were transfected with siRNAs specific against Bid or Bim. Forty-eight hours after transfection, the specificity and efficacy of knockdown were controlled by western blot with antibodies as indicated. (f-h) Knockdown of Bid, Bim or both reduced apoptotic cell death induced by anti-APO-1 (CD95), TRAIL and etoposide. The experiments were performed as in (b and c). Results are representative of three independent experiments each performed in duplicate assays

cells towards anti-CD95- and TRAIL-induced apoptotic cell death (Figure 5f). These results demonstrate that Taxmediated overexpression of HIF-1a is responsible for the suppression of Bim and Bid expression.

Targeting HIF-1a by chetomin restores Bim and Bid expression and enhances anti-CD95/TRAIL- and anticancer drug-induced apoptosis in HTLV-1-infected cells. As HIF-1a was shown to have an important role in the survival of HTLV-1-infected cells, we asked whether HIF-1a could be a therapeutic target for treatment of Tax-expressing $T$ cells. To address this question, chetomin, which inhibits HIF-1 transactivation activity by interfering with the interaction of HIF-1a with the coactivator $\mathrm{p} 300,{ }^{30}$ was used to treat the HTLV-1-infected T-cell lines MT-2 and MT-4. Inhibition of HIF-1a activity by chetomin resulted in an increase in Bim and Bid expression in MT-2 and MT-4 cells (Figure 6a and Supplementary Figure S4A). In contrast, p21, whose expression is positively regulated by HIF- $1 a$, ${ }^{31}$ was downregulated by chetomin (Figure 6a). Tax levels were not affected by chetomin (Figure 6a). Therefore, enhanced expression of Bim and Bid by chetomin was not due to the suppression of Tax expression. Chetomin-mediated upregulation of Bim and Bid expression was shown to correlate with enhanced apoptotic cell death induced by anti-CD95, TRAIL and the anticancer drugs etoposide and doxorubicin in MT-2 and SP cells (Figures 6b-e and Supplementary Figure S4B). Thus, HIF-1a may be a potential therapeutic target for treatment of HTLV-1 infectious diseases.

Taken together, Bid and Bim have been shown to promote apoptosis by both inhibition of antiapoptotic Bcl-2 members and activation of Bak and $\mathrm{Bax}^{16-20}$ (Figure 6f). In this study, we show that Bid and Bim expression is suppressed in HTLV-1infected cells through Tax-mediated elevation of the protein levels of the transcription factor HIF-1a. We also show that targeting HIF-1a may restore Bid and Bim expression and enhance chemo- and receptor-mediated apoptosis in HTLV-1infected T cells (Figure 6f).

\section{Discussion}

Upregulation of antiapoptotic proteins by the HTLV-1 protein Tax has been implicated in apoptosis resistance of infected cells. ${ }^{6-11}$ In this study, we show that not only expression levels of antiapoptotic proteins but also proapoptotic proteins are dysregulated in HTLV-infected cells. We discovered that expression levels of the $\mathrm{BH} 3$-only proteins Bid and Bim are downregulated at the transcriptional level in HTLV-1-infected 
a

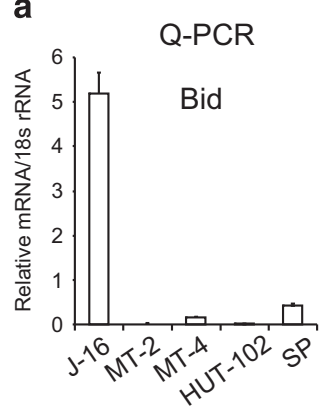

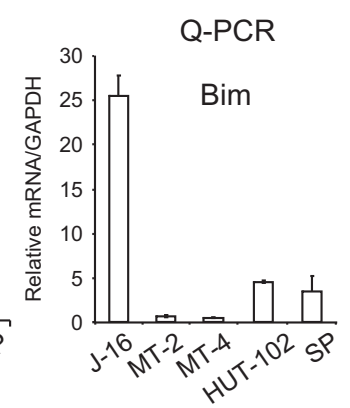

b

T cell leukemia HTLV-1-ATL
C

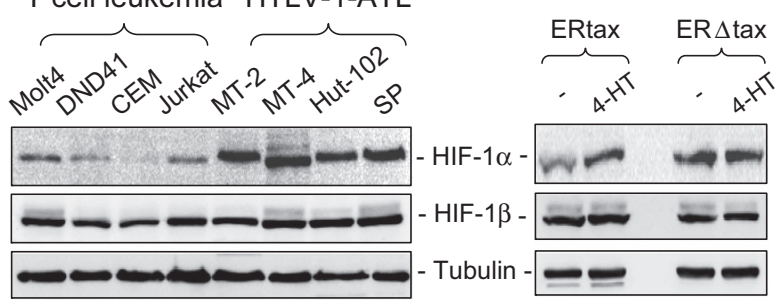

d

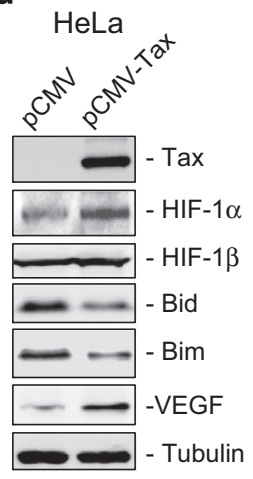

e

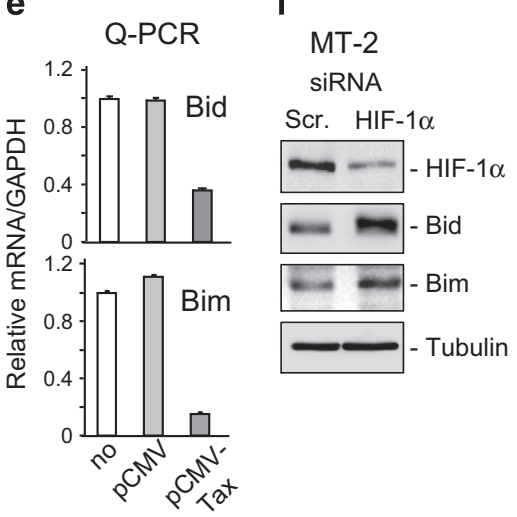

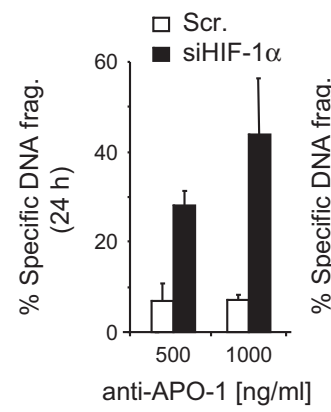

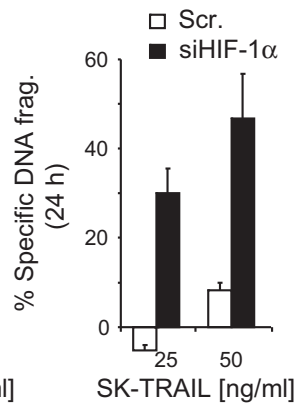

Figure 5 Tax suppresses Bim and Bid expression at the transcriptional level by the upregulation of HIF-1 $\alpha$ protein expression. (a) Bid and Bim mRNA expression is downregulated in HTLV-1-Tax-expressing cells. The mRNA expression levels of Bid and Bim in MT-2, MT-4, Hut-102 and SP were compared with the non-HTLV-1-infected leukemic T-cell line Jurkat by q-PCR. Results are representative of two independent experiments each performed in triplicate assays. (b) HTLV-1-Tax-expressing T cells express elevated levels of HIF- $1 \alpha$ proteins. Western blot analysis of the expression levels of HIF- $1 \alpha$ and HIF- $1 \beta$ protein in MT-2, MT-4, Hut-102 and SP cells. Molt-4, DND-41, CEM and Jurkat cells were used as controls. Representative blots from three independent experiments are shown. (c and d). Increased HIF-1 $\alpha$ protein expression correlates with Tax expression. (c) Jurkat ERtax or ER $\Delta$ tax cells were stimulated by $4-\mathrm{TH}(5 \mu \mathrm{M})$ for $40 \mathrm{~h}$ and then subjected to western blot analysis with antibodies against HIF-1 $\alpha$ and $\mathrm{HIF}-1 \beta$ as indicated. Representative blots from two independent experiments are shown. (d) HeLa cells were transiently transfected with a Tax expression plasmid pCMV-Tax or empty plasmid pCMV. Twenty-four hours after transfection, total cell lysates were subjected to western blot analysis with antibodies as indicated. The HIF-1 target gene VEGF was used as a positive control. Representative blots from two independent experiments are shown. (e) Ectopic expression of Tax in HeLa cells downregulates Bim and Bid expression at the transcriptional level. HeLa cells were transfected with pCMV-Tax as in (d). Twenty-four hours after tansfection, Bim and Bid expression was analyzed by q-PCR. Results are representative of two independent experiments each performed in triplicate assays. (f) Knockdown of HIF-1 $\alpha$ enhances Bim and Bid expression and enhances anti-CD95- and TRAIL-mediated apoptosis in HTLV-1-infected ATL cells. MT-2 cells were transfected with HIF-1 $\alpha$ siRNA. Seventy-two hours after transfection, the protein levels of HIF-1 $\alpha$, Bim and Bid were examined by western blot analysis (left panel). Representative blots from two independent experiments are shown. HIF- $1 \alpha$ siRNA-transfected MT-2 cells were treated with different concentrations of anti-APO-1 (CD95) or TRAlL (right panel) for $24 \mathrm{~h}$. Apoptotic cell death was determined by DNA fragmentation. Results are representative of two independent experiments each performed in duplicate assays

cells and that this downregulation is mediated by Tax. We also demonstrate that downregulation of Bid and Bim expression in HTLV-1-infected T cells has a significant impact on apoptosis resistance to anti-CD95, TRAIL and anticancer drugs (Figure 6f).

Up to now, the most successful treatment strategy for ATL patients has been reported to be a combination of the anti-viral drug Zidovudine (AZT) with interferon- $a$ (IFN- $a) .{ }^{32}$ However, combinational chemotherapy, the so-called VCAP-AMPVECP: vincristine, cyclophosphamide, doxorubicin and prednisone (VCAP), doxorubicin, ranimustine and prednisone (AMP) and vindesine, etoposide, carboplatin and prednisone (VECP), ${ }^{33}$ achieved only a 3 -year survival rate in $24 \%$ of ATL patients in Japan. ${ }^{5}$ We tested four HTLV-1-positive T-cell lines with regard to their responses to doxorubicin and etoposide. All cell lines showed complete (Figure 1a) or significant (Figure1b) resistance to etoposide and doxorubicin compared with the non-HTLV-1-infected leukemic T-cell line Jurkat, indicating that ATL cells are highly resistant to chemotherapy.
A systematic analysis of the expression levels of anti- and proapoptotic proteins in HTLV-1 Tax-expressing cell lines revealed that in addition to an increase in antiapoptotic proteins (Figure 1c), conversely, the expression levels of the $\mathrm{BH} 3-$ only proteins Bim and Bid were diminished (Figure 2a). This observation was further confirmed by analyzing HTLV-1infected $\mathrm{CD}^{+} \mathrm{T}$ cells from ATL patients (Figure $2 \mathrm{~b}$ ) and by overexpression of Tax in non-Tax-expressing cells (Figures 2c and d).

Embryo fibroblasts and $\mathrm{T}$ cells from $\mathrm{Bid}^{-1-}$ and $\mathrm{Bim}^{-1-}$ double-knockout mice were shown to be resistant to diverse apoptotic stimuli, for example, UV-irradiation, $\gamma$-irradiation, tunicamycin and etopside. ${ }^{20,33}$ Thus, we predicted that reduction of $\mathrm{Bim}$ and Bid expression may contribute to apoptosis resistance of HTLV-1-infected T cells. To test this prediction, we carried out two experiments: ectopic expression of Bim and Bid in MT-2 and Hut-102 cells and knockdown of Bim or Bid using an siRNA approach in Jurkat and HeLa cells. Consistent with previous studies, ${ }^{20,34}$ our experiments 


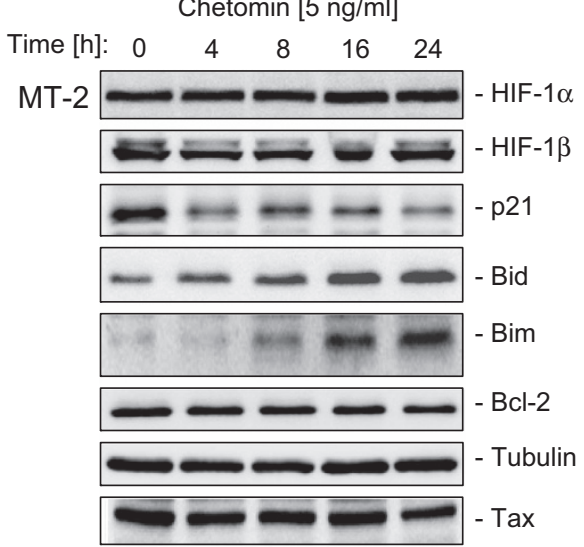

b

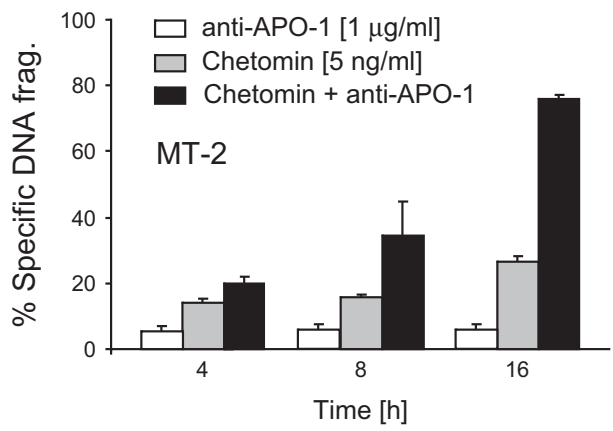

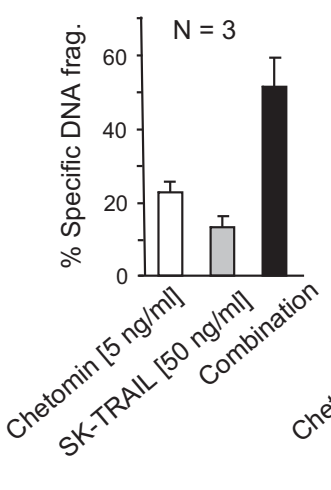

d

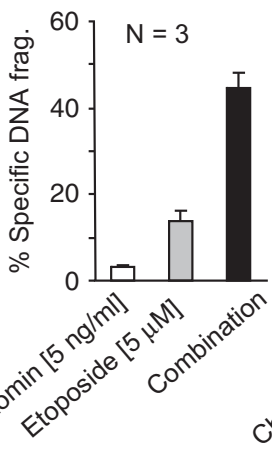

e

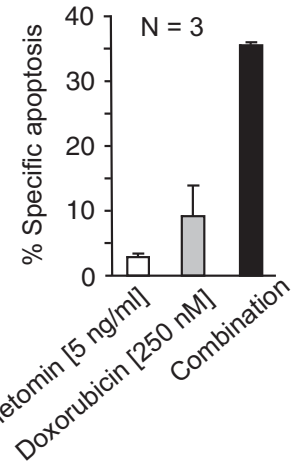

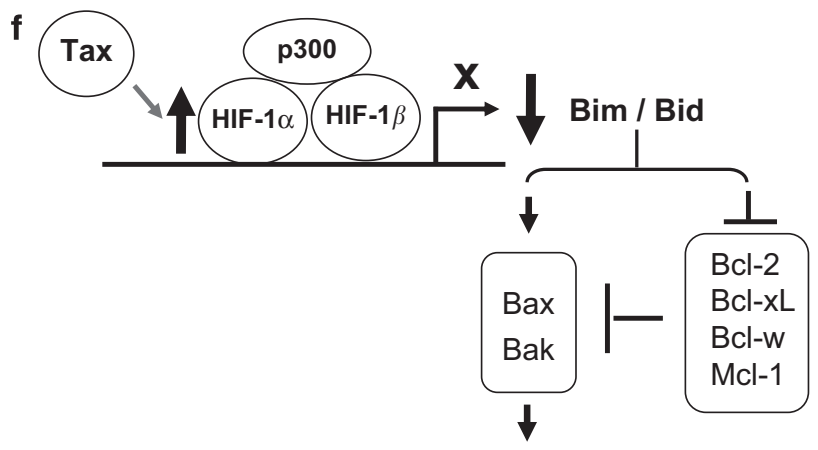

Apoptosis

Figure 6 Inhibition of HIF-1 $\alpha$ transactivation activity in HTLV-1-infected T cells enhances anti-CD95-, TAIL- and anticancer drug-induced cell death. (a) Inhibition of HIF-1 $\alpha$ transactivation activity by chetomin enhances Bid and Bim expression in HTLV-1-infected T cells. MT-2 cells were treated with chetomin $(5 \mathrm{ng} / \mathrm{ml})$ for different time periods as indicated. The effect of chetomin on Bim and Bid expression was examined by western blot analysis. The HIF-1 $\alpha$ target gene p21 was used as a positive control for the inhibitory effect of chetomin on HIF- $1 \alpha$. The non-HIF- $1 \alpha$ target genes $B c l-2$ and Tax were used as specificity controls. Representative blots from two independent experiments are shown. (b-e) Inhibition of HIF-1 $\alpha$ transactivation activity by chetomin enhances sensitivity of HTLV-1-infected T cells towards anti-CD95-, TAIL- and anticancer drug-induced cell death. MT-2 cells were preincubated with chetomin $(5 \mathrm{ng} / \mathrm{ml})$ for $24 \mathrm{~h}$ and then treated without (solvents) or with anti-APO-1 (CD95) $(1 \mu \mathrm{g} / \mathrm{ml})$, TRAlL (50 ng/ml), etoposide ( $5 \mu \mathrm{M})$ or doxorubicin $(250 \mathrm{nM})$ for $24 \mathrm{~h}$. Results are representative of three independent experiments each performed in duplicate assays. (f) Schematic description of Tax-mediated downregulation of Bid and Bim expression via enhancing HIF- $1 \alpha$ protein level and the consequent reduction in apoptosis

confirmed that Bim and Bid had an important role in apoptosis induction by etoposide, anti-CD95 antibody and TRAIL in leukemic $\mathrm{T}$ cells (Figure 3 and Supplementary Figure S1; Figure 4 and Supplementary Figure S3).

Bim and Bid not only have overlapping functions but also show selectivities. ${ }^{35}$ Bim interacts with Bax but not Bak, whereas Bid can interact with Bax and Bak after processing by caspases into its active form tBid. Bim binds all five prosurvival proteins, whereas tBid binds potently to $\mathrm{Mcl}-1$ and $\mathrm{Bcl}-\mathrm{xL}$. Furthermore, Bak activation requires the neutralization of only $\mathrm{Bcl}-\mathrm{xL}$ and $\mathrm{Mcl}-1$, whereas Bax-mediated apoptosis requires the additional neutralization of $\mathrm{Bcl}-2$, and probably $\mathrm{Bcl}-\mathrm{w}$. Consistent with these facts, we observed that knockdown of both Bim and Bid resulted in a further resistance to apoptosis induction compared with that seen by knockdown of either one. We show that HIF-1a suppresses both Bim and Bid expression (Figure 6a). Thus, HIF-1a may be a good therapeutic target in HTLV-1-infected cells (Figure 6f). We also observed an enhancement of Bax expression in HTLV-1infected cell lines. Further experiments confirmed that enhanced Bax expression is regulated by Tax but not by HIF-1a (unpublished data).

Comparison of mRNA expression levels of Bid and Bim in HTLV-1-infected and non-infected cells revealed a substantial reduction of Bid and Bim mRNA expression in HTLV-1-infected cells (Figure 5a). As HIF-1 has been implicated in transcriptional suppression of $\mathrm{Bim}$ and Bid expression in several systems, ${ }^{26-29}$ we examined the HIF-1 protein levels in HTLV-1Tax-expressing T-cell lines. All cell lines tested showed a significant elevation of HIF-1a protein (Figure $5 \mathrm{~b}$ ). Using the Jurkat-ERTax/ER $\Delta$ Tax-inducible system, we demonstrated that Tax expression is tightly associated with the elevation of HIF-1a (Figure 5c). To further examine the role of Tax in the upregulation of HIF-1a, in general, we transiently transfected a Tax expression plasmid into HeLa cells. The experiment showed that ectopic expression of Tax in HeLa cells enhanced HIF-1 a protein expression, which correlated with a reduction in Bim and Bid expression at the transcriptional level (Figures $5 d$ and e). Several studies have linked the inverse correlation between HIF-1a and Bim/Bid expression to chemo- and radiotherapy resistance in different types of 
cancer. ${ }^{26,28,29,36,37}$ Consistent with these studies, we could show that knockdown of HIF-1a in MT-2 cells by siRNA led to an increase in Bim and Bid expression and rendered the cells more sensitive to anti-CD95- and TRAIL-induced apoptosis (Figures $5 f$ and $g$ ). Thus, HIF-1 a may have an important role in apoptosis resistance in HTLV-infected cells.

HIF-1a expression is regulated mainly by two distinct mechanisms: an oxygen-dependent mechanism that often occurs in hypoxic tissues or hypoxic tumor areas and an oxygen-independent mechanism through PI3K/AKT-mediated protein synthesis. ${ }^{38} \mathrm{PI} \mathrm{K}$ is a target of Tax. Tax can bind to PI3K and stimulates the phosphorylation of AKT and, consequently, increases translation. ${ }^{39}$ Therefore, in HTLV-1infected cells, Tax may increase HIF-1 $a$ by accelerating HIF-1a protein synthesis.

The tumor suppressor p53 has been shown to bind to the Bid promoter p53-responsive sequence and activate Bid transcription. ${ }^{40}$ However, in HTLV-1-infected cells, p53 transcriptional activity has been shown to be inhibited by Tax by the constitutive activation of NF-KB (p65), resulting in the formation of a p65-p53 complex at the p53-responsive promoter sequence and blocking recruitment of important cofactors. ${ }^{41,42}$ Thus, inactivation of p53 transcriptional activity by Tax may also be involved in the reduction of Bid expression in HTLV-1-infected cells. To test this possibility, we used an NF- $\kappa$ B inhibitor to inhibit NF- $\kappa$ B activity in SP cells. Inhibition of $N F-k B$ activity indeed showed an increase in Bid expression but at a low degree (data not shown). Thus, we conclude that Tax-mediated elevation of HIF-1a is the important mechanism that causes the downregulation of Bid expression.

It has been shown that Tax physically interacts with the proteasome core and enhances proteolytic activity. ${ }^{43} \mathrm{~A}$ recent study shows that proteasome inhibitor MG132 upregulates Bim protein levels by reducing activated ERK, a negative regulator of Bim expression. ${ }^{44}$ Thus, Tax-mediated increase in proteolytic activity may also be involved in the reduction of Bim expression in HTLV-1-infected cells.

$\mathrm{HIF}-1 a$ is overexpressed in many types of cancer and its overexpression correlates with chemo- and radiotherapy resistance. ${ }^{45-47}$ Therefore, HIF-1a has been considered to be a therapeutic target in cancer treatment. ${ }^{37}$ To investigate the potential of HIF-1a as a therapeutic target for the treatment of HTLV-1-infected T cells, chetomin, which inhibits the HIF-1a transactivation activity by blocking the interaction of HIF-1a with its cofactor $\mathrm{p} 300,{ }^{30}$ was used in our experiments. The study showed that inhibition of HIF-1a activity by chetomin restored Bim and Bid expression in HTLV-1-infected cells (Figure 6a and Supplementary Figure S4A). Consequently, chetomin treatment significantly enhanced anti-CD95-, TRAIL-, etoposide- and doxorubicin-induced apoptotic cell death in HTLV-1-infected cells (Figures $6 \mathrm{~b}-\mathrm{e}$ and Supplementary Figure S4B). These results suggest that HIF-1a may be a potential target for the treatment of HTLV-1 infectious diseases. During the past decade, inhibitors that specifically target HIF-1a, for example, EZN-2968 (Enzon Pharmaceuticals Inc., Piscataway, NJ, USA and Santaris Pharma A/S, Roche Innovation Center Copenhagen A/S, Hørsholm, Denmark), an RNA antagonist that specifically targets HIF-1a mRNA and PX-478 (S-2-amino-3-[4'-N,N,-bis (2-chloroethyl)amino]phenyl propionic acid $\mathrm{N}$-oxide), which inhibits HIF-1a protein synthesis, have been tested in various tumors and have achieved promising results in vitro and in vivo in animal tumor models. ${ }^{48-50}$ PX-478 and EZN-2968 are currently evaluated in phase I clinical trials. Our data may stimulate further investigations of treatment of HTLV-1infected patients by specific HIF-1a inhibitors.

\section{Materials and Methods}

Cell lines and culture. The human malignant cell lines used in this study are the human acute T-lymphoblastic leukemia cell lines Molt- $4,{ }^{51}$ DND- $41,{ }^{52}$ CEM, ${ }^{53}$ Jurkat, ${ }^{54}$ Jurkat stably transfected with an ERtax or an ER $\Delta$ tax whose expression can be induced by $4-\mathrm{HT}^{24}$ the cervical cell line HeLa ${ }^{55}$ and the HTLV-1-transformed human T-cell leukemia cell lines MT-2 ${ }^{56,57}$ and MT-4 ${ }^{58}$ the HTLV-1-infected ATL cell lines Hut-102 ${ }^{59}$ and $\mathrm{SP}^{60}$ All cells were cultured at $37^{\circ} \mathrm{C}$ and $5 \% \mathrm{CO}_{2}$ in RPMI-1640 or DMEM (Gibco Laboratories, Grand Island, NE, USA), supplemented with $10 \% \mathrm{FCS}, 100 \mathrm{U} / \mathrm{ml}$ penicillin (Gibco), $100 \mu \mathrm{g} / \mathrm{ml}$ streptomycin (Gibco) and $2 \mathrm{mM} \mathrm{L-glutamine} \mathrm{(Gibco).} \mathrm{SP} \mathrm{cells} \mathrm{were} \mathrm{cultured} \mathrm{with} \mathrm{an} \mathrm{additional} \mathrm{supplement} \mathrm{of}$ $50 \mathrm{U} / \mathrm{ml} \mathrm{IL-2}$ as described previously. ${ }^{60}$ Primary leukemic samples from HTLV-1infected patients were kindly supplied by Charles RM Bangham (Department of Immunology, Imperial College, Wright-Fleming Institute, Norfolk Place, London, UK).

Determination of apoptosis. Cells were treated with different concentrations of anti-APO-1 antibodies, ${ }^{61}$ SuperKiller-TRAIL (Enzo Life Sciences, New York, NY, USA), etoposide (Sigma-Aldrich, St Louis, MO, USA), doxorubicin (SigmaAldrich) or chetomin (Enzo Life Sciences) for different time periods as indicated in the figure legends. Apoptotic cell death was examined by the analysis of DNA fragmentation according to the method of Nicoletti as described previously. ${ }^{8}$ Results are presented as the percent of specific DNA fragmentation using the formula: (percentage of experimental apoptosis - percentage of spontaneous apoptosis)/ $(100-$ percentage of spontaneous apoptosis $) \times 100$.

Western blot analysis. A total of $1 \times 10^{6}$ cells were lysed for each sample, as described previously. ${ }^{25,62}$ Equal amounts of protein were separated on $7.5-13 \%$ SDS-PAGE depending on the molecular size of the proteins of interest, blotted onto a nitrocellulose membrane (Amersham Biociences, Little Chalfon, UK) and blocked with $5 \%$ non-fat dry milk in PBS/Tween (0.05\% Tween-20 in PBS). Antibodies directed against the following proteins were used: anti-c-Flip was made by our own laboratory, ${ }^{63}$ anti-Bad, -Bak, -Bax, -Bcl-xL, -Bcl-w, -Bid, -Bim, -HIF-1 $\alpha,-H I F-1 \beta$, -Puma, -VEGF and -XIAP were purchased from Cell Signaling Technology (Danvers, MA, USA); anti-Bcl-2, -Mcl-1, -p21 and -p27 were purchased from Santa Cruz Biotechnology (Heidelberg, Germany); anti-Tax from NIH (Hybridoma, Bethesda, MD, USA; cat. no. 1312); anti-tubulin and -actin were purchased from Sigma-Aldrich (Munich, Germany).

Quantitative real-time PCR. RNA was isolated from $1 \times 10^{6}$ cells per preparation, using the RNeasy Mini Kit (Qiagen, Hilden, Germany) according to the manufacturer's instructions. One microgram of total RNA was reverse transcribed using the Perkin-Elmer GeneAmp RNA PCR Kit (Foster City, CA, USA). For TaqMan quantitative real-time $\mathrm{PCR}$, primers and fluorescent-labeled probes for the human Bid, Bim and 18S rRNA were purchased from Sigma-Aldrich (Germany). The levels of mRNA relative to $18 \mathrm{~S}$ rRNA or GAPDH were calculated using the formula: relative mRNA expression $=2^{-\left(C_{t} \text { of Bid/Bim }-C_{t} \text { of } 18 \mathrm{~S} \mathrm{rRNA}\right)}$, whereas $C_{t}$ is the respective threshold cycle value.

Transient transfection studies. Two micrograms of Bid or Bim expression plasmids (Thermo Fisher Scientific, Waltham, MA, USA) were transfected into MT-2 cells using Nucleofector solution (Nucleofector Kit V, program 0-17; Amaxa Biosystems, Cologne, Germany) according to the manufacturer's instructions. Fortyeight hours after transfection, cells were collected for protein expression analysis by western blot and for treatment as indicated in the figure legends. Jurkat and HeLa cells were transfected with 5 and $8 \mu \mathrm{g}$ Tax expression plasmid, ${ }^{24}$ respectively. Jurkat cells were transfected using electroporation with a Gene Pulser II at $250 \mathrm{~V}$ and $950 \mu \mathrm{F}$ (Bio-Rad, Hercules, CA, USA) and transfection of HeLa cells was carried out using Lipofectamine 2000 (Invitrogen, Paisley, UK) according to the manufacturer's instructions. Cells were collected $24-48 \mathrm{~h}$ after transfection for protein expression analysis. 
Knockdown studies. Jurkat cells $\left(2 \times 10^{6}\right)$ were transfected in Nucleofector solution (Nucleofector Kit V, program X-01; Amaxa Biosystems) with $2 \mu \mathrm{M}$ of nonsense siRNA (Qiagen), Bid siRNA (Qiagen) or Bim siRNA (Qiagen) using the Nucleofector apparatus. MT-2 cells were transfected in Nucleofector solution (Nucleofector Kit V, program 0-17; Amaxa Biosystems) with $2 \mu \mathrm{M}$ of nonsense siRNA (Qiagen) or HIF-1 $\alpha$ siRNA (Qiagen). Seventy-two hours after transfection, cells were collected for protein expression analysis and different treatments as indicated in the figure legends.

\section{Conflict of Interest}

The authors declare no conflict of interest.

Acknowledgements. We thank Charles RM Bangham for providing samples from ATL patients. This work was supported by the Helmholtz Alliance on Immunotherapy of Cancer and the Deutsches Konsortium für Translationale Krebsforschung (DKTK)

1. Yoshida M. Discovery of HTLV-1, the first human retrovirus, its unique regulatory mechanisms, and insights into pathogenesis. Oncogene 2005; 24: 5931-5937.

2. Gessain $A$, Cassar $O$. Epidemiological aspects and world distribution of HTLV-1 infection. Front Microbiol 2012; 3: 388

3. Taylor GP, Matsuoka M. Natural history of adult T-cell leukemia/lymphoma and approaches to therapy. Oncogene 2005; 24: 6047-6057.

4. Matsuoka M, Jeang KT. Human T-cell leukaemia virus type 1 (HTLV-1) infectivity and cellular transformation. Nat Rev Cancer 2007; 7: 270-280.

5. Matsuoka M, Jeang KT. Human T-cell leukemia virus type 1 (HTLV-1) and leukemic transformation: viral infectivity, Tax, HBZ and therapy. Oncogene 2011; 30: 1379-1389.

6. Tsukahara $\mathrm{T}$, Kannagi $\mathrm{M}$, Ohashi $\mathrm{T}$, Kato $\mathrm{H}$, Arai $\mathrm{M}$, Nunez $\mathrm{G}$ et al. Induction of $\mathrm{Bcl}-\mathrm{x}(\mathrm{L})$ expression by human T-cell leukemia virus type 1 Tax through NF-kappaB in apoptosisresistant T-cell transfectants with Tax. J Virol 1999; 73: 7981-7987.

7. Nicot $\mathrm{C}$, Mahieux R, Takemoto S, Franchini $\mathrm{G}$. Bcl- $\mathrm{X}(\mathrm{L})$ is up-regulated by HTLV-I and HTLV-II in vitro and in ex vivo ATLL samples. Blood 2000; 96: 275-281.

8. Krueger A, Fas SC, Giaisi M, Bleumink M, Merling A, Stumpf C et al. HTLV-1 Tax protects against CD95-mediated apoptosis by induction of the cellular FLICE-inhibitory protein (c-FLIP). Blood 2006; 107: 3933-3939.

9. Okamoto K, Fujisawa J, Reth M, Yonehara S. Human T-cell leukemia virus type-I oncoprotein Tax inhibits Fas-mediated apoptosis by inducing cellular FLIP through activation of NF-kappaB. Genes Cells 2006; 11: 177-191.

10. Swaims AY, Khani F, Zhang Y, Roberts Al, Devadas S, Shi Y et al. Immune activation induces immortalization of HTLV-1 LTR-Tax transgenic CD4+ T cells. Blood 2010; 116: 2994-3003.

11. Macaire H, Riquet A, Moncollin V, Biemont-Trescol MC, Duc Dodon M, Hermine $\mathrm{O}$ et al. Tax protein-induced expression of antiapoptotic Bfl-1 protein contributes to survival of human T-cell leukemia virus type 1 (HTLV-1)-infected T-cells. J Biol Chem 2012; 287: 21357-21370.

12. Lindsten $T$, Ross AJ, King A, Zong WX, Rathmell JC, Shiels HA et al. The combined functions of proapoptotic Bcl-2 family members bak and bax are essential for norma development of multiple tissues. Mol Cell 2000; 6: 1389-1399.

13. Wei MC, Zong WX, Cheng EH, Lindsten T, Panoutsakopoulou V, Ross AJ et al. Proapoptotic BAX and BAK: a requisite gateway to mitochondrial dysfunction and death. Science 2001 292: 727-730.

14. Giam M, Huang DC, Bouillet P. BH3-only proteins and their roles in programmed cell death. Oncogene 2009; 27(Suppl 1): S128-S136.

15. Zong WX, Lindsten T, Ross AJ, MacGregor GR, Thompson CB. BH3-only proteins that bind pro-survival Bcl-2 family members fail to induce apoptosis in the absence of Bax and Bak. Genes Dev 2001; 15: 1481-1486.

16. Cartron PF, Gallenne T, Bougras G, Gautier F, Manero F, Vusio P et al. The first alpha helix of Bax plays a necessary role in its ligand-induced activation by the $\mathrm{BH}$-only proteins $\mathrm{Bid}$ and PUMA. Mol Cell 2004; 16: 807-818.

17. Chen L, Willis SN, Wei A, Smith BJ, Fletcher JI, Hinds MG et al. Differential targeting of prosurvival $\mathrm{Bcl}-2$ proteins by their $\mathrm{BH}$-only ligands allows complementary apoptotic function. Mol Cell 2005; 17: 393-403.

18. Marani M, Tenev T, Hancock D, Downward J, Lemoine NR. Identification of novel isoforms of the $\mathrm{BH} 3$ domain protein Bim which directly activate Bax to trigger apoptosis. Mol Cell Biol 2002; 22: 3577-3589.

19. Wang K, Yin XM, Chao DT, Milliman CL, Korsmeyer SJ. BID: a novel BH3 domain-only death agonist. Genes Dev 1996; 10: 2859-2869.

20. Willis SN, Fletcher Jl, Kaufmann T, van Delft MF, Chen L, Czabotar PE et al. Apoptosis initiated when $\mathrm{BH} 3$ ligands engage multiple Bcl-2 homologs, not Bax or Bak. Science 2007 315: 856-859.

21. Akita K, Kawata S, Shimotohno K. p21WAF1 modulates NF-kappaB signaling and induces anti-apoptotic protein Bcl-2 in Tax-expressing rat fibroblast. Virology 2005; 332: 249-257.

22. Czabotar PE, Colman PM, Huang DC. Bax activation by Bim? Cell Death Differ 2009; 16 $1187-1191$
23. Ott M, Norberg E, Zhivotovsky B, Orrenius S. Mitochondrial targeting of tBid/Bax: a role for the TOM complex? Cell Death Differ 2009; 16: 1075-82.

24. Chlichlia K, Moldenhauer G, Daniel PT, Busslinger M, Gazzolo L, Schirrmacher V et al. Immediate effects of reversible HTLV-1 tax function: T-cell activation and apoptosis. Oncogene 1995; 10: 269-277.

25. Bleumink M, Kohler R, Giaisi M, Proksch P, Krammer PH, Li-Weber M. Rocaglamide breaks TRAIL resistance in HTLV-1-associated adult T-cell leukemia/lymphoma by translational suppression of c-FLIP expression. Cell Death Differ 2011; 18: 362-370.

26. Erler JT, Cawthorne CJ, Williams KJ, Koritzinsky M, Wouters BG, Wilson C et al. Hypoxia-mediated down-regulation of Bid and Bax in tumors occurs via hypoxia-inducible factor 1-dependent and -independent mechanisms and contributes to drug resistance. Mol Cell Biol 2004; 24: 2875-2889.

27. Xie L, Johnson RS, Freeman RS. Inhibition of NGF deprivation-induced death by low oxygen involves suppression of BIMEL and activation of HIF-1. J Cell Biol 2005; 168: 911-920.

28. Seenath MM, Roberts D, Cawthorne C, Saunders MP, Armstrong GR, O'Dwyer ST et al. Reciprocal relationship between expression of hypoxia inducible factor 1alpha (HIF-1alpha) and the pro-apoptotic protein bid in ex vivo colorectal cancer. Br J Cancer 2008; 99: 459-463.

29. Whelan KA, Caldwell SA, Shahriari KS, Jackson SR, Franchetti LD, Johannes GJ et al. Hypoxia suppression of Bim and Bmf blocks anoikis and luminal clearing during mammary morphogenesis. Mol Biol Cell 2010; 21: 3829-3837.

30. Kung AL, Zabludoff SD, France DS, Freedman SJ, Tanner EA, Vieira A et al. Small molecule blockade of transcriptional coactivation of the hypoxia-inducible factor pathway. Cancer Cell 2004; 6: 33-43

31. Goda N, Ryan HE, Khadivi B, McNulty W, Rickert RC, Johnson RS. Hypoxia-inducible factor 1alpha is essential for cell cycle arrest during hypoxia. Mol Cell Biol 2003; 23: 359-369.

32. Bazarbachi A, Plumelle Y, Carlos Ramos J, Tortevoye P, Otrock Z, Taylor G et al. Meta-analysis on the use of zidovudine and interferon-alfa in adult T-cell leukemia/ lymphoma showing improved survival in the leukemic subtypes. J Clin Oncol 2010; 28: 4177-4183.

33. Tsukasaki K, Utsunomiya A, Fukuda $H$, Shibata $T$, Fukushima $T$, Takatsuka $Y$ et al. VCAP-AMP-VECP compared with biweekly CHOP for adult T-cell leukemia-lymphoma: Japan Clinical Oncology Group Study JCOG9801. J Clin Oncol 2007; 25: 5458-5464.

34. Ren D, Tu HC, Kim H, Wang GX, Bean GR, Takeuchi O et al. BID, BIM, and PUMA are essential for activation of the BAX-and BAK-dependent cell death program. Science 2010; 330: $1390-1393$.

35. Fletcher Jl, Huang DC. Controlling the cell death mediators Bax and Bak: puzzles and conundrums. Cell Cycle 2008; 7: 39-44.

36. Deeb G, Vaughan MM, McInnis I, Ford LA, Sait SN, Starostik P et al. Hypoxia-inducible factor-1alpha protein expression is associated with poor survival in normal karyotype adult acute myeloid leukemia. Leuk Res 2011; 35: 579-584.

37. Whelan KA, Reginato MJ. Surviving without oxygen: Hypoxia regulation of mammary morphogenesis and anoikis. Cell Cycle 2011: 10.

38. Semenza GL. Targeting HIF-1 for cancer therapy. Nat Rev Cancer 2003; 3: 721-732.

39. Peloponese JM Jr, Jeang KT. Role for Akt/protein kinase B and activator protein-1 in cellular proliferation induced by the human T-cell leukemia virus type 1 tax oncoprotein. J Biol Chem 2006; 281: 8927-8938

40. Sax JK, Fei P, Murphy ME, Bernhard E, Korsmeyer SJ, El-Deiry WS. BID regulation by p53 contributes to chemosensitivity. Nat Cell Biol 2002; 4: 842-849.

41. Pise-Masison CA, Mahieux R, Radonovich M, Jiang H, Duvall J, Guillerm C et al. Insights into the molecular mechanism of p53 inhibition by HTLV type 1 Tax. AIDS Res Hum Retroviruses 2000; 16: 1669-1675.

42. Jeong SJ, Radonovich M, Brady JN, Pise-Masison CA. HTLV-I Tax induces a novel interaction between p65/RelA and p53 that results in inhibition of p53 transcriptional activity. Blood 2004; 104: 1490-1497.

43. Kfoury $Y$, Nasr R, Hermine $O$, de Théand $H$, Bazarbachi A. Proapoptotic regimes for HTLV-I-transformed cells: targeting Tax and the NF-kappaB pathway. Cell Death Differ 2005: 871-877.

44. Westerberg $\mathrm{CM}$, Hägglund $\mathrm{H}$, Nilsson $\mathrm{G}$. Proteasome inhibition upregulates Bim and induces caspase-3-dependent apoptosis in human mast cells expressing the Kit D816V mutation. Cell Death Dis 2012; 3: e417.

45. Talks KL, Turley H, Gatter KC, Maxwell PH, Pugh CW, Ratcliffe PJ et al. The expression and distribution of the hypoxia-inducible factors HIF-1alpha and HIF-2alpha in normal human tissues, cancers, and tumor-associated macrophages. Am J Pathol 2000; 157: 411-421.

46. Rankin EB, Giaccia AJ. The role of hypoxia-inducible factors in tumorigenesis. Cell Death Differ 2008: 15: 678-685.

47. Rohwer N, Cramer T. Hypoxia-mediated drug resistance: novel insights on the functional interaction of HIFs and cell death pathways. Drug Resist Updat 2011; 14: 191-201.

48. Greenberger LM, Horak ID, Filpula D, Sapra P, Westergaard M, Frydenlund HF et al. A RNA antagonist of hypoxia-inducible factor-1alpha, EZN-2968, inhibits tumor cell growth. Mol Cancer Ther 2008; 7: 3598-3608.

49. Koh MY, Spivak-Kroizman T, Venturini S, Welsh S, Williams RR, Kirkpatrick DL et al. Molecular mechanisms for the activity of PX-478, an antitumor inhibitor of the hypoxia-inducible factor-1alpha. Mol Cancer Ther 2008; 7: 90-100. 
50. Schwartz DL, Bankson JA, Lemos R Jr., Lai SY, Thittai AK, He Y et al. Radiosensitization and stromal imaging response correlates for the HIF-1 inhibitor PX-478 given with or without chemotherapy in pancreatic cancer. Mol Cancer Ther 2010; 9: 2057-2067.

51. Minowada J, Onuma T, Moore GE. Rosette-forming human lymphoid cell lines. I. Establishment and evidence for origin of thymus-derived lymphocytes. I Natl Cancer Inst 1972; 49: 891-895.

52. Seon BK, Negoro S, Barcos MP, Tebbi CK, Chervinsky D, Fukukawa T. Monoclonal antibody SN2 defining a human T cell leukemia-associated cell surface glycoprotein. J Immunol 1984; 132: 2089-2095.

53. Kapoor R, Slade DL, Fujimori A, Pommier Y, Harker WG. Altered topoisomerase I expression in two subclones of human CEM leukemia selected for resistance to camptothecin. Oncol Res 1995; 7: 83-95.

54. Weiss A, Wiskocil RL, Stobo JD. The role of T3 surface molecules in the activation of human T cells: a two-stimulus requirement for IL 2 production reflects events occurring at a pre-translational level. J Immunol 1984; 133: 123-128.

55. Scherer WF, Syverton JT, Gey GO. Studies on the propagation in vitro of poliomyelitis viruses. IV. Viral multiplication in a stable strain of human malignant epithelial cells (strain HeLa) derived from an epidermoid carcinoma of the cervix. J Exp Med 1953; 97: 695-710.

56. Harada S, Koyanagi Y, Yamamoto N. Infection of HTLV-III/LAV in HTLV-I-carrying cells MT-2 and MT-4 and application in a plaque assay. Science 1985; 229: 563-566.

57. Miyoshi I, Kubonishi I, Yoshimoto S, Shiraishi Y. A T-cell line derived from normal human cord leukocytes by co-culturing with human leukemic T-cells. Gann 1981; 72: 978-981.

58. Pauwels R, De Clercq E, Desmyter J, Balzarini J, Goubau P, Herdewijn P et al. Sensitive and rapid assay on MT-4 cells for detection of antiviral compounds against the AIDS virus. J Virol Methods 1987; 16: 171-185.
59. Poiesz BJ, Ruscetti FW, Gazdar AF, Bunn PA, Minna JD, Gallo RC. Detection and isolation of type $C$ retrovirus particles from fresh and cultured lymphocytes of a patient with cutaneous T-cell lymphoma. Proc Natl Acad Sci USA 1980; 77: 7415-7419.

60. Rowe T, Dezzutti C, Guenthner PC, Lam L, Hodge T, Lairmore MD et al. Characterization of a HTLV-I-infected cell line derived from a patient with adult T-cell leukemia with stable co-expression of CD4 and CD8. Leuk Res 1995; 19: 621-628.

61. Trauth BC, Klas C, Peters AM, Matzku S, Moller P, Falk W et al. Monoclonal antibody-mediated tumor regression by induction of apoptosis. Science 1989; 245: 301-305.

62. Baumann S, Fas SC, Giaisi M, Muller WW, Merling A, Gulow K et al. Wogonin preferentially kills malignant lymphocytes and suppresses T-cell tumor growth by inducing PLCgamma1and $\mathrm{Ca}^{2+}$-dependent apoptosis. Blood 2008; 111: 2354-2363.

63. Scaffidi C, Schmitz I, Krammer PH, Peter ME. The role of C-FLIP in modulation of CD95-induced apoptosis. J Biol Chem 1999; 274: 1541-1548.

(c) (i) Cell Death and Disease is an open-access journal published by Nature Publishing Group. This work is licensed under a Creative Commons Attribution 4.0 International Licence. The images or other third party material in this article are included in the article's Creative Commons licence, unless indicated otherwise in the credit line; if the material is not included under the Creative Commons licence, users will need to obtain permission from the licence holder to reproduce the material. To view a copy of this licence, visit http://creativecommons.org/licenses/by/4.0

Supplementary Information accompanies this paper on Cell Death and Disease website (http://www.nature.com/cddis) 